\title{
Evaluation of the Role of Medial Open Wedge Osteostomy with Use of External Ring Fixator in Osteoarthrosis of the Knee in Rural Population
}

\author{
Dr. Charudatta V. Shinde, M.S. MCh ( Orthopaedics ) \\ Additional Civil Surgeon District Dhule Maharashtra. India 424001.
}

\begin{abstract}
In this era of increasing life expectancy and change in the lifestyle, osteoarthrosis of weight bearing joints, particularly the knee joint has become the most common Orthopaedic problem of enormous magnitude. Medial opened wedge tibial osteotomy fixed with standard ring fixator will be very useful for them as being of low cost and giving them immediate pain free mobilization, so that they can carry out their routine activities freely and as early as possible.

Aim and Objectives: To study clinicoradiological findings in cases of Medial compartment osteoarthritis of knee joint. To evaluate the role of Medial opened wedge tibial osteotomy aiming to relieve pain, correct deformity and improve function. To study Biomechanics of knee joint with special reference to knee in osteoarthritis. To study the relevant literature. To compare the results with other available series.

Results: 23 cases of medial compartmental osteoarthrosis of knee joint, who were subjected to Medial open wedge high tibial osteotomy, were studied. Osteoarthrosis of knee joint was found to be common in patients between 45 to 65 years of age [82.60\%] Most of the patients had right sided involvement [65.22\%]. In some patients, patello-femoral arthritis became less severe. In the present study $52.81 \%$ patients had 5 to 8degree varus angulation and one patient had 2degree of valgus angulation pre-operatively. Excellent relief of pain in knee can be achieved in patients who presented earlier i.e. whose complaints were of less than 1 year duration. 30 to 50 of over correction are essential t3o unload the medial compartment of the joint. The knee which maintains $5^{\circ}$ to $14^{\circ}$ of Valgus angulation post-operatively ended with radiologically satisfactory results [78\%]. $82.58 \%$ patients obtained clinically worthwhile relief of pain following Medial opened wedge tibial osteotomy.
\end{abstract}

\section{Introduction}

Osteoarthrosis or osteoarthritis is not a disease by itself. It is the effect of degenerative processes. Osteoarthrosis is a well-known entity even before the understanding of biomechanics of joint and its effect on articular cartilage. This disease leaves a long lasting impact on the personality due to the loss of confidence, depression and social isolation. Hence the need for the treatment of osteoarthrosis has become essential. Thus in such a fast moving world it has become absolute mandatory to offer some solution to the problems produced by osteoarthrosis.

Osteoarthrosis can involve any population irrespective of geographical location or climate [1]. After the age of 60 years large population suffer from osteoarthrosis of the knee joint [2]. This is one of the major causes for morbidity at that age, which increases with age.

Pathological studies have shown that the knee joint is the most commonly affected joint by osteoarthrosis as compared to other joint in the body. [HEINE, 1926] [3] This is the result of aging.

It is now well proved fact that out of total body weight, $60 \%$ of weight is transmitted by muscles and $40 \%$ by bones [4].

This study has been carried out in rural population where patient are from a low socioeconomic status as they are many a times the bread earners of the family. Medial opened wedge tibial osteotomy fixed with standard ring fixator will be very useful for them as being of low cost and giving them immediate pain free mobilization, so that they can carry out their routine activities freely and as early as possible.

\section{Aims And Objectives}

To study clinicoradiological findings in cases of Medial compartment osteoarthritis of knee joint.

To evaluate the role of Medial opened wedge tibial osteotomy aiming to relieve pain, correct deformity and improve function.

To study Biomechanics of knee joint with special reference to knee in osteoarthritis.

To study the relevant literature.

To compare the results with other available series. 


\section{Materials And Method}

The patients for the present study of A clinical study of role of Medial opened wedge tibial osteotomy in medial compartment osteoarthrosis of knee were selected from cases of osteoarthrosis of knees attending Orthopaedic O.P.O. of Pravara Rural Hospital, Loni between the period form July 2001 to June 2003. Uniform surgical technique and post - operative regimen were followed in all cases. After confirmation of diagnosis, most of our patients were given a conservative trial of treatment. Finally surgery was advised to the patients for the following indications:

1) Patients complaining of knee joint pain while walking squatting or at rest, or leading to disability that interfere significantly with employment or recreation which is unrelieved by conservative treatment.

2) The presence of osteoarthrosis changes on weight bearing roentgenograms mainly of the medial compartment, symptoms. With symptoms.

3) Loss of normal valgus angulation or varus deformity up to $12^{\circ}$ to $150^{\circ}$.

4) Absence of gross instability of the knee joint.

5) Fixed flexion deformity of 100 or less and a range of flexion at knee of 700 or more with evidence of medial compartment osteoarthrosis.

6) Patient should be physical fit to carry out rehabilitation post operatively [able to use crutches and to do simple exercises].

7) Vascular status of the extremity should be compitent in every patient.

8) Patient should not be over weight.

\section{ASSESSMENT OF RESULTS}

The operative results are graded according to subjective and objective findings with particular emphasis on

1. Relief of pain

2. Restoration of movement

3. Correction of deformity

\section{GRADING OF RESULTS}

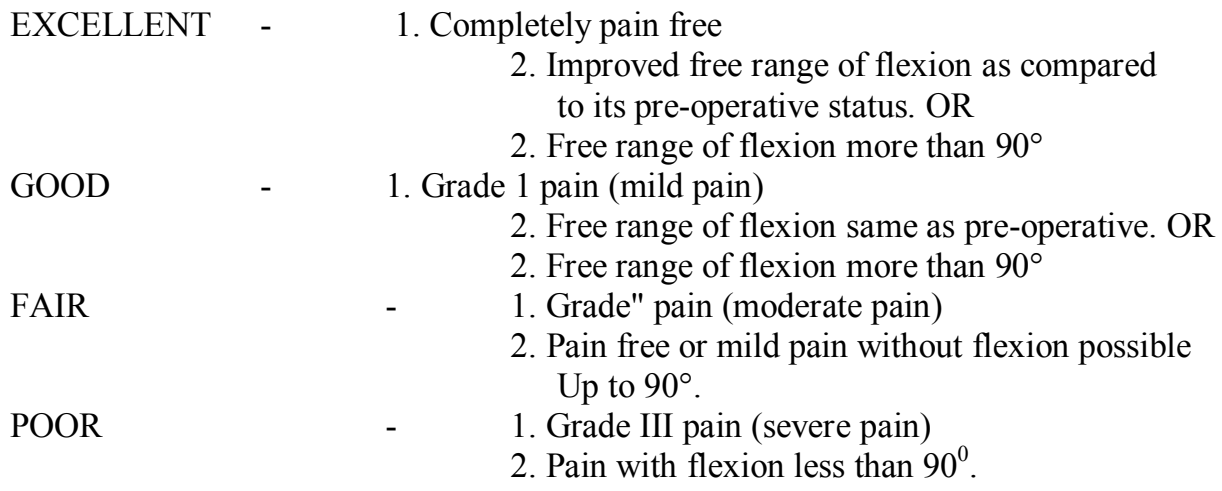

\section{RADIOLOGICAL ASSESSMENT}

The radiological assessment was also carried out to study the relation between the post-operative Tibio - femoral angle and the results using the criteria employed by Coventry (1965) [5].

$5^{\circ}-13^{\circ}$ valgus alignment is ideal and has satisfactory results.

Grade I - The knee that maintained $5^{\circ}-13^{\circ}$ of valgus as shown by Coventry (1965) [5] Insall (1974) [6] Maquet (1976)[7].

Grade II - The knee in which the alignment was not ideal with less than $5^{\circ}$ or more than $14^{\circ}$ of valgus alignment.

\section{Observation Tables}

In the present series, 23 patients were subjected to Medial opened wedge tibial osteotomy stabilized with external ring fixator for medial compartment osteoarthrosis of knee joint.

\section{AGE AND SEX DISTRIBUTION}

In the present series, $56.52 \%$ patients were between 45 to 50 yrs of age. The average age was 54 yrs. 
Evaluation of the Role of Medial Open Wedge Osteostomy with Use of External Ring....

TABLE -1 AGE AND SEX DISTRIBUTION

\begin{tabular}{|c|c|c|c|c|}
\hline \multirow[t]{2}{*}{ AGE IN YRS. } & \multicolumn{2}{|c|}{ SEX } & \multirow[t]{2}{*}{ TOTAL } & \multirow[t]{2}{*}{ PERCENTAGE } \\
\hline & MALE & FEMALE & & \\
\hline Below 45 yrs. & $\mathrm{O}$ & 2 & 2 & $8.70 \%$ \\
\hline $44-55$ yrs. & 3 & 10 & 13 & $56.52 \%$ \\
\hline $55-65$ yrs. & 3 & 3 & 6 & $26.08 \%$ \\
\hline Above 65 yrs. & 1 & 1 & 2 & $8.70 \%$ \\
\hline TOTAL & 7 & 16 & 23 & $100 \%$ \\
\hline Percentage & $30.43 \%$ & 69 & & $100 \%$ \\
\hline
\end{tabular}
i.e. $30.43 \%$

In the present series, out of 23 patients 16 patients were female i.e. $69.57 \%$ and 7 patients were male

\section{WEIGHT OF THE PATIENT}

Majority of patients in this series had weight between $50-70 \mathrm{~kg}(73.92 \%)$

\begin{tabular}{|c|c|c|c|c|}
\hline \multirow{2}{*}{$\begin{array}{l}\text { WEIGHT OF } \\
\text { PATIENT }\end{array}$} & \multicolumn{2}{|c|}{ NO. OF CASES } & \multirow[b]{2}{*}{ TOTAL } & \multirow[t]{2}{*}{ PERCENTAGE } \\
\hline & MALE & FEMALE & & \\
\hline Below $50 \mathrm{~kg}$ & 0 & 3 & 3 & $13.04 \%$ \\
\hline $50-70 \mathrm{~kg}$ & 5 & 12 & 17 & $73.92 \%$ \\
\hline Above $70 \mathrm{~kg}$ & 2 & 1 & 3 & $13.04 \%$ \\
\hline TOTAL & 7 & 16 & 23 & $100 \%$ \\
\hline
\end{tabular}

SIDE OF INVOLVEMENT

Majority of patients in this present study had Right sided involvement (65.22\%).

TABLE - III SIDE OF INVOLVEMENT

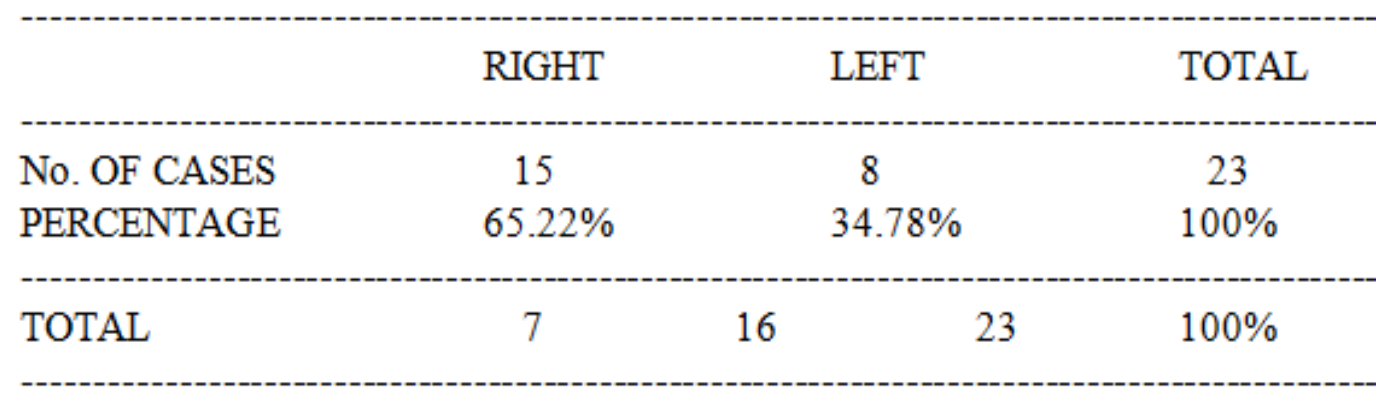

PREOPERATIVE DURATION OF OSTEOARTHROSIS OF KNEE duration

Most of the patients in this series had complaints of osteoarthrosis (mostly pain) of more than $1 \mathrm{yr}$. of

\begin{tabular}{lcc}
\multicolumn{1}{l}{ TABLE - IV PREOPERATIVE DURATION OF OSTEOARTHROSIS OF KNEE } \\
\hline DURATION IN YRS. & NO. OF PATIENTS PERCENTAGE \\
\hline Below 1 yrs. & 7 & $30.43 \%$ \\
Above 1 yrs & 16 & $69.57 \%$ \\
\hline TOTAL & 23 & $100 \%$ \\
\hline
\end{tabular}




\section{ASSOCIATION WITH PATELLO-FEMORAL ARTHRITIS}

$43.48 \%$ patients in this series were associated with mild to moderate patellofemoral arthritis.

TABLE V - ASSOCIATION WITH PA TELLO-FEMORAL ARTHRITIS

$\begin{array}{llcc}\begin{array}{l}\text { PATELLO-FEMORAL } \\ \text { ARTHRITIS }\end{array} & \text { NO. OF PATIENTS PERCENTAGE } \\ \text { PRESENT } & \begin{array}{l}\text { MILD - 4 } \\ \text { MODERATE - 6 } \\ \text { SEVERE-O }\end{array} & 10 & 43.48 \% \\ \text { ABSENT } & & 13 & 56.52 \% \\ \text { TOTAL } & & 23 & 100 \%\end{array}$

GRADING OF PAIN

Pre-operatively $60.87 \%$ of knees gave continuous severe pain i.e. grade III in this present study.

TABLE VI - GRADING OF PAIN

$\begin{array}{lcc}\text { GRADE } & \text { NO. OF PATIENTS } & \text { PERCENTAGE } \\ \text { II } & 1 & 4.35 \% \\ \text { II } & 8 & 34.78 \% \\ \text { II } & 14 & 60.87 \% \\ \text { TOTAL } & 23 & 100 \%\end{array}$

\section{DEFORMITY}

In the present study 12 patients i.e. $52.18 \%$ had 5080 varus angulation pre-operatively. One patient had $2^{\circ}$ valgus angulation showing medial compartment osteoarthrosis radiologically along with significant clinical findings.

TABLE VII - DEFORMITY

VARUS ANGULATION NO. OF PATIENTS $\quad$ PERCENT
IN DEGREES

\begin{tabular}{lll}
$0-4$ & 7 & $30.43 \%$ \\
$0-8$ & 12 & $52.18 \%$ \\
9 and above & 3 & $13.03 \%$ \\
ONE PATIENT HAD & 1 & $4.35 \%$ \\
VALGUS ANGULATION & & \\
\hline TOTAL & 23 & $100 \%$ \\
\hline
\end{tabular}

\section{RANGE OF MOVEMENT PRE-OPERATIVELY}

$73.90 \%$ patients had 1260 and more free flexion range of movement pre-operatively. 


\begin{tabular}{lcc}
\multicolumn{1}{c}{ TABLE VIII } & - RANGE OF MOVEMENT PRE-OPERATIVELY \\
\hline FLEXION IN & & \\
DEGREES & NO. OF PATIENTS & PERCENTAGE \\
\hline $85-95$ & 0 & 0 \\
$96-105$ & 1 & $4.35 \%$ \\
$106-115$ & 1 & $4.35 \%$ \\
$116-125$ & 4 & $17.40 \%$ \\
126 and above & 17 & $73.90 \%$ \\
$--------100 \%$
\end{tabular}

\section{RADIOLOGICAL GRADINGS OF OSTEOARTHROSIS OF KNEE}

$60.87 \%$ of patient was grouped in IV i.e. osteoarthritic changes showing joint space $2 \mathrm{~mm}$ or less [given in material and method].

TABLE - IX RADIOLOGICAL GRADINGS OF OSTEOARTHROSIS OF KNEE

\begin{tabular}{lll}
\hline GRADE & NO. OF PATIENTS & PERCENTAGE \\
\hline I & 0 & 0 \\
II & 0 & 0 \\
III & 3 & $13.03 \%$ \\
IV & 14 & $60.87 \%$ \\
V & 6 & $26.10 \%$ \\
VI & 0 & 0 \\
TOTAL & 23 & $100 \%$ \\
\hline
\end{tabular}

\section{POST - OSTEOTOMY RADIOLOGICAL GRADINGS OF OSTEOARTHROSIS OF KNEE}

In our present series not much of radiological changes occurred [degeneration or regeneration] postoperatively as compared to preoperative, except for the opening of joint space.

\section{TABLE X POST - OSTEOTOMY RADIOLOGICAL GRADINGS OF OSTEOARTHROSIS OF KNEE}

\begin{tabular}{lll} 
GRADE & NO. OF PATIENTS & PERCENTAGE \\
I & 0 & 0 \\
II & 0 & 0 \\
III & 13 & $56.52 \%$ \\
IV & 8 & $34.78 \%$ \\
V & 2 & $8.70 \%$ \\
VI & 0 & 0 \\
\hline TOTAL & 23 & $100 \%$
\end{tabular}

\section{GRADING OF PAIN - POST - OPERATIVE COMPARE WITH PRE - OPERATIVE}

When comparison was made in between pre-operative and postoperative grading of pain, it showed almost reversal of polarity. At follow up 56.12\% patients were completely free of pain. 
Evaluation of the Role of Medial Open Wedge Osteostomy with Use of External Ring....

\begin{tabular}{ccccc} 
TABLE XI & \multicolumn{2}{c}{ GRADING OF PAIN - POST - OPERATIVE COMPARED WITH PRE - OPERAT } \\
GRADING OF PAIN & \multicolumn{2}{c}{ PRE } & \multicolumn{2}{c}{ POST } \\
OPERATIVE & OPERATIVE \\
\hline NO PAIN & 0 & $(0 \%)$ & 13 & $(56.52 \%)$ \\
I & 1 & $(4.35 \%)$ & 7 & $(30.43 \%)$ \\
II & 8 & $(34.78 \%)$ & 3 & $(13.5 \%)$ \\
III & 14 & $(60.87 \%)$ & 0 & $(0 \%)$ \\
\hline TOTAL & 23 & $(100 \%)$ & 23 & $(100 \%)$ \\
\hline
\end{tabular}

\section{RANGE OF MOVEMENT POST - OPERATIVELY.}

$73.90 \%$ patients had 1260 and more free range of flexion postoperatively. In $17.40 \%$ patients, range of movement was improved while in $8.70 \%$ patients range of movement was worsened post operatively.

\begin{tabular}{lcc}
\multicolumn{1}{c}{ TABLE-XII } & RANGE OF MOVEMENT - POST - OPERATIVELY. \\
\hline DEGREES & NO. OF PATIENTS & PERCENTAGE \\
\hline $85-95$ & 1 & $4.35 \%$ \\
$96-105$ & 0 & $0 \%$ \\
$106-115$ & 1 & $4.35 \%$ \\
$116-125$ & 4 & $17.40 \%$ \\
126 and above & 17 & $73.90 \%$ \\
- \hdashline$O T A L$ & 23 & $100 \%$
\end{tabular}

\section{TABLE XIII RANGE OF MOVEMENT}

\begin{tabular}{|c|c|c|c|c|c|}
\hline MOVEMENT & $95-105$ & $106-115$ & $116-125$ & \multicolumn{2}{|c|}{$\begin{array}{c}126 \text { and TOTAL } \\
\text { Above }\end{array}$} \\
\hline IMPROVEMENT & 1 & 1 & 2 & 0 & 4 \\
\hline SAME & 0 & 0 & 2 & 15 & 17 \\
\hline WORSE & 0 & 0 & 0 & 2 & 2 \\
\hline TOTAL & 1 & 1 & 4 & 17 & 23 \\
\hline
\end{tabular}

\section{POST-OPERATIVE VALGUS ANGULATION} operatively.

In the present study we had patients having $5^{\circ}$ to $14^{\circ}$ valgus angulation in $78 \%$ patients post TABLE XIV POST-OPERATIVE VALGUS ANGULATION

\begin{tabular}{lcc}
$\begin{array}{l}\text { VALGUS ANGULATION } \\
\text { (Degrees) }\end{array}$ & NO. OF PATIENTS & PERCENTAGE \\
\hline Less than $5^{\circ}$ & 5 & 22 \\
$5^{\circ}$ to $14^{\circ}$ & 18 & 78 \\
More than $14^{\circ}$ & 0 & 0 \\
\hline
\end{tabular}




\section{WEIGHT BEARING}

In the present study partial weight bearing with support was started at 4th week (avg.) and full weight bearing without support was started at 10th week (avg.).

\section{TABLE XV WEIGHT BEARING PERIOD}

\section{WEIGHT BEARING}

Partial weight bearing

With support

Full weight bearing without

Support
AVERAGE DURATION

8 to 10 days

3 months

\section{DURATION OF Follow - UP}

$82.60 \%$ patients had more than 1 year follow up in this present study. The minimum post-op. follow-up (6 months. - 12 months) was in $17.39 \%$ patients.

\begin{tabular}{lcc} 
& TABLE XVI & DURATION OF Follow - UP \\
DURATION & NO. OF PATIENTS & PERCENTAGE \\
IN MTH & & \\
\hline 6 MTH - $12 \mathrm{MTH}$ & 4 & $17.39 \%$ \\
$13 \mathrm{MTH}-18 \mathrm{MTH}$ & 10 & $33.48 \%$ \\
$18 \mathrm{MTH}-24 \mathrm{MTH}$ & 9 & $100 \%$ \\
\hline TOTAL & 23 & \\
\hline
\end{tabular}

\section{COMPLICATIONS}

The complications seen in this series were as follows:

\section{TABLE XVII COMPLICATIONS}

COMPLICATIONS NO. OF CASES PERCENTAGE

INTRAOPERATIVE

$\begin{array}{lll}\text { Intraarticular Fracture } & 0 & 0 \\ \text { Neurovascular } & 0 & 0 \\ \text { Complications } & & \end{array}$

POST - OPERATIVE

Infection:

Superficial

Deep

Weakness of ankle

Dorsiflexors

Delayed union

Non union

Deep Venous

Thrombosis

Death
2

1

2

1

0

0

0
$8.6 \%$

$4.35 \%$

$8.6 \%$

$4.35 \%$

$0 \%$

$0 \%$

$0 \%$ 


\section{RESULTS: CLINICAL} results.

In the present study, $56.50 \%$ patients showed excellent results and $26.08 \%$ patients showed good

TABLE XVIII RESULTS

\begin{tabular}{lcc}
\hline GRADE & NO. OF PATIENTS & PERCENTAGE \\
\hdashline EXCELLENT & 13 & $56.50 \%$ \\
GOOD & 6 & $26.08 \%$ \\
FAIR & 4 & $17.40 \%$ \\
POOR & 0 & $0 \%$
\end{tabular}

RESULTS: RADIOLOGICAL

In the present study, $78 \%$ patients had valgus alignment between $5^{\circ}$ to $13^{\circ}$ post-operatively.

\begin{tabular}{|c|c|c|c|c|c|}
\hline \multirow{3}{*}{ GROUP } & \multirow{3}{*}{ TOTAL KNEE } & \multicolumn{2}{|r|}{ RESULTS } & & \multirow[b]{2}{*}{ RESULT } \\
\hline & & & VALGUS & $\%$ & \\
\hline & & \multicolumn{3}{|c|}{ ANGULATION } & \\
\hline I & 18 & \multicolumn{2}{|c|}{$5^{\circ}-13^{\circ}$} & $78^{\circ}$ & ACTORY \\
\hline II & 5 & \multicolumn{2}{|c|}{$<5^{\circ}->14^{\circ}$} & $22^{\circ}$ & ISFACT. \\
\hline
\end{tabular}

\section{Summary And Conclusions}

- In the present series, 23 cases of medial compartmental osteoarthrosis of knee joint, who were subjected to Medial open wedge high tibial osteotomy, were studied between July 2001 to July 2003.

- Osteoarthrosis of knee joint we found to be common in patients between 45 to 65 years of age [82.60\%], in over weighted patients it was earlier and was more severe.

- Majority Le. $69.57 \%$ patients were females and $31.43 \%$ were males.

- Most of the patients had right sided involvement [65.22\%].

- In Medial compartment osteoarthrosis varus deformity of varying degree was commonly found.

- Most of the patients had complaints about osteoarthrosis of more than 1 year duration [69.57\%].

- Many of the patients of present study had patella femoral arthritis [43.48\%] and could be responsible, at least to some extent, for the persistent or recurrence of pain following osteotomy. In some patients, patello-femoral arthritis became less severe.

- In the present study $52.81 \%$ patients had 5 to 8 degree varus angulation and one patient had 2 degree of valgus angulation pre-operatively.

- External ring fixator serves as an adequate fixation, which allow early mobilization and was enough to maintain correction.

- As the bone was externally fixed, and the site of osteotomy was at the cortical bone region bone grafting is done to reduce chances of delayed or nonunion.

- In $91.30 \%$ patients, range of movement remained same or increased as compared to that pre-operatively.

- When comparison was made between pre-operative and post operative grading of pain, it showed almost reversal of polarity.

- Marked radiological improvement is uncommon following osteotomy although joint space had increased and subchondral sclerosis decreased.

- Partial weight bearing was started after an average period of 8 to 10 days, and full weight bearing was started on 3 months.

- Patients were followed up for 6-24 monthb. $82.60 \%$ patients were followed up for more than 1 year.

- Minor complications occurred in 6 out of 23 patients. Complications seen were in the form of infection, delayed union, weakness of ankle dorsiflexors.

- Advanced age did not seem to be a contraindication for the osteotomy and showed good results. 
- Excellent relief of pain in knee can be achieved in patients who presented earlier i.e. whose complaints were of less than 1 year duration.

- $\quad 3^{0}$ to $5^{0}$ of over correction are essential t3o unload the medial compartment of the joint. The knee which maintains $5^{\circ}$ to $14^{\circ}$ of Valgus angulation post-operatively ended with radiologically satisfactory results [78\%].

- $82.58 \%$ patients obtained clinically worthwhile relief of pain following Medial opened wedge tibial osteotomy.

- Follow up of all cases that were in good results category, showed continued relief of pain and good range of movement.

- Results of the present series are comparable to other published series of high tibial osteotomies.

\section{Conclusions}

$>$ In properly selected cases and with proper technique, medial open wedge high tibial osteotomy is a reliable surgical procedure. It is a surgical treatment of choice in young and active patients with over $80 \%$ good results, where other recent modalities of treatment are not easily available to every patient. A long lasting relief of pain and a good range of movement can be assured post -operatively.

$>$ To get good results and to avoid complications, pre-operative assessment and planning is essential.

$>$ The social conditions in our area for e.g. sitting cross legs, squatting for daily activities, hence we have thought of this procedure.

$>$ Our series confined it self to a low socio-economic status, which made patient, refuse for total knee arthroplasty. Which, if at all required in future, can also be done after Medial open wedge tibial osteotomy.

$>$ This procedure is technically simple, safe without any potential hazard, and can be done in remote places. Good amount of correction is possible by this procedure.

$>$ Medial opened wedge tibial osteotomy fixed with standard ring fixator will be very useful for them as being of low cost and giving them immediate pain free mobilization, so that they can carry out their routine activities freely and as early as possible.

$>$ The procedure is simple, safe and effective method. It is a small operation with negligible blood loss and no blood transfusion is required. No anesthesia is necessary to remove the apparatus.

$>$ The fact that all of the patients requiring bilateral osteotomy return for the operation to be performed on the opposite side speaks for itself.

\section{BIBLIOGRAPHY}

[1]. Lawrance and Sebo; "Geography of osteoarthritis" in the Aetiopathogenesis of Osteoarthritis, edited by Nuki - 1980 [London-Pitman] Page No. 155

[2]. Koshino Tomihisa - Clinical, findings and aetielogy of osteoarthrosis of the knee Asian Medical Journal Vol. -10 No. 11 Nov. 1987

[3]. Jackson J.P., Waugh w., Green J.P; "High Tibial Osteotomy for Osteoarthritis of the Knee" JBJS 51 -B, P 88,1969

[4]. Gibson P.J., Good fellow J. - stress radiography in degenerative arthritis of the knee JBJS Vol. 68 - B No.4 Aug. 1986. P. -608

[5]. Coventry M.B; "Osteotomy of the Tibia for Osteoarthritis of the knee" JBJS 47 - A, P 984-90, 1965

[6]. Insall J.N. , Shoji H, Mayer V; "High Tibial Osteotomy - 5 year evaluation"JBJS 56-A, P 1397,1974

[7]. Maquet P.G.J; CORR - No. 120, P143, 1976 


\section{CASE photos:}

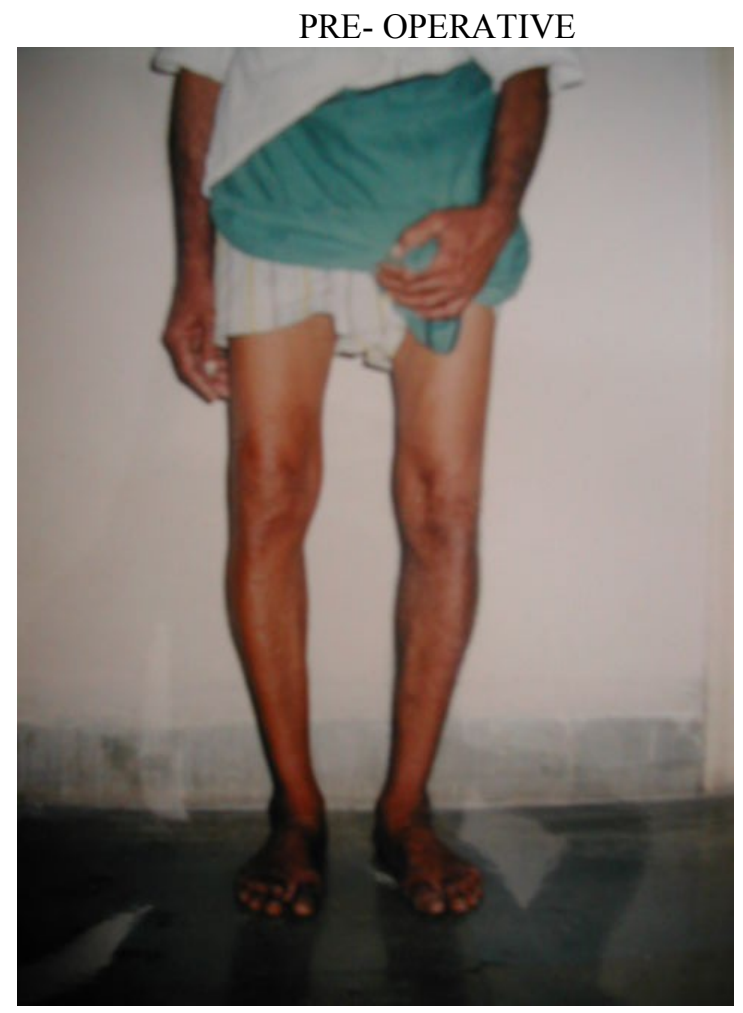

ON DISCHARGE $\left[12^{\text {th }}\right.$ Day $]$

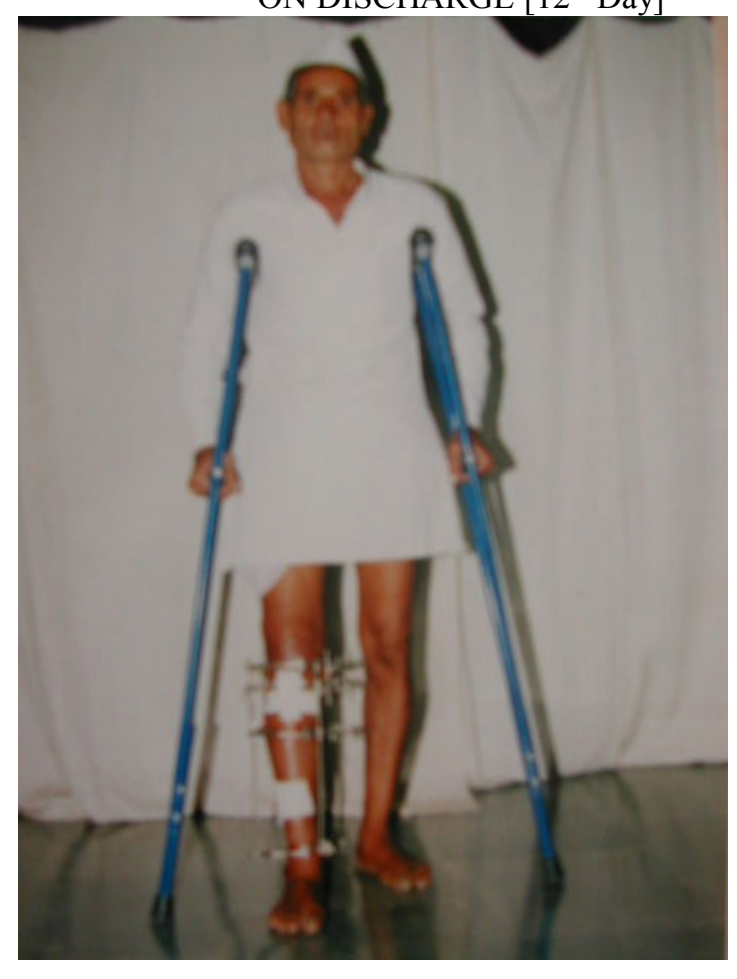

IMMEDIATE POST- OPERATIVE

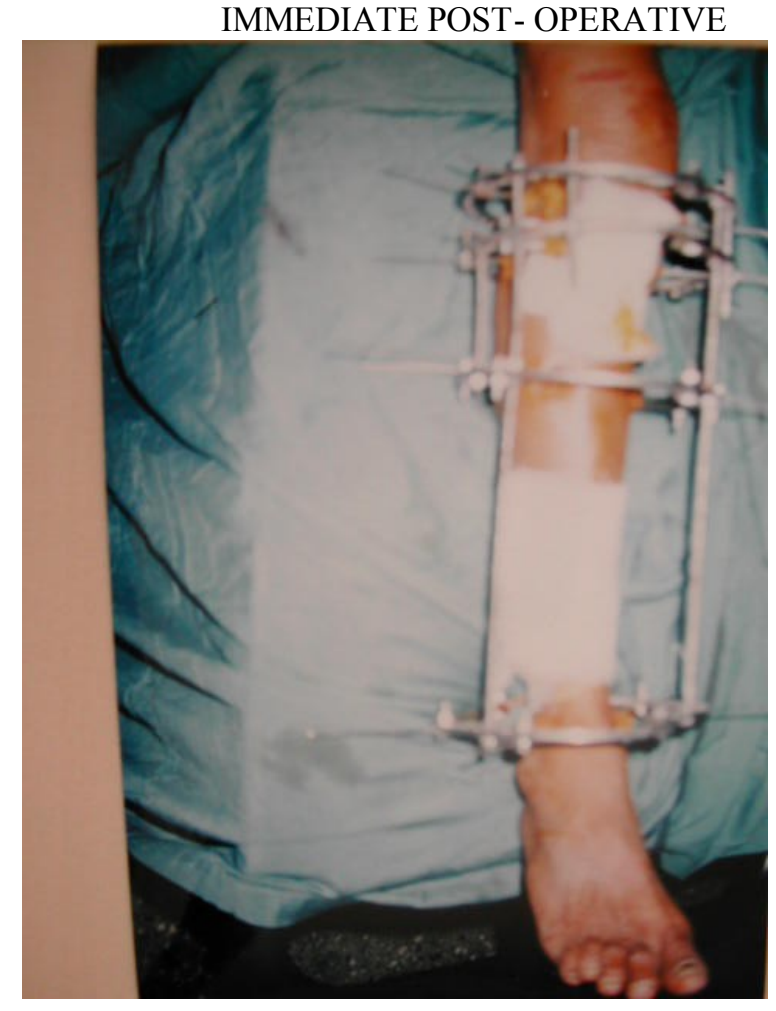

FOLLOW UP [AFTER 2 MONTHS]

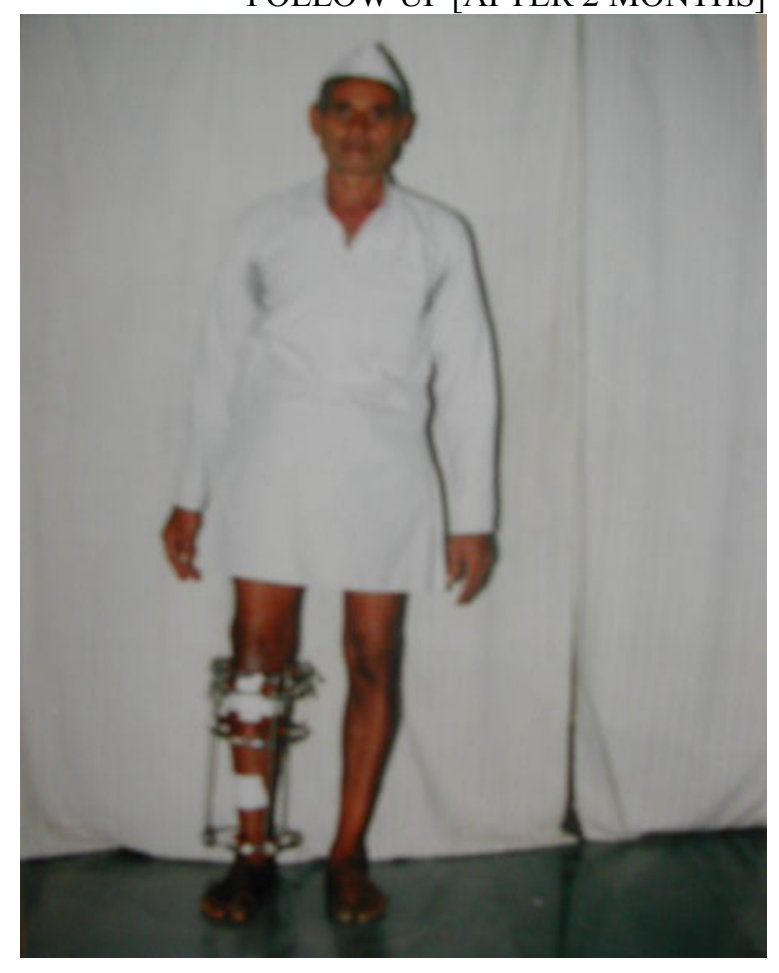


FOLLOW UP [AFTER 2 MONTHS]
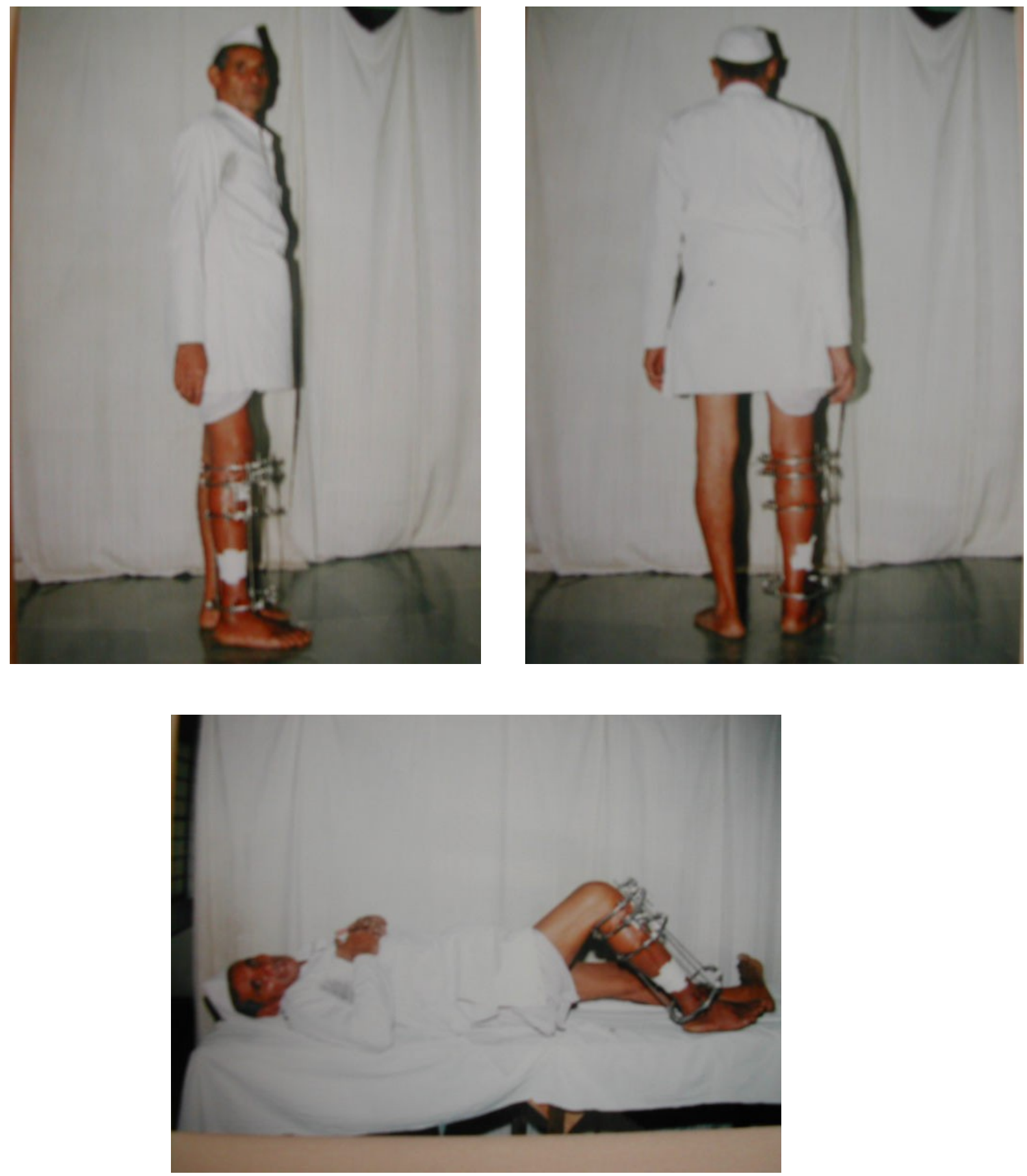